\title{
Characteristics and potential sources of atmospheric particulate mercury in Jinan, China
}

\author{
Yaxin $\mathrm{Li}^{\text {a }}$, Yan Wang ${ }^{\mathrm{a}, *}$, Yan $\mathrm{Li}^{\mathrm{b}}{ }^{\mathrm{b}}$, Tao $\mathrm{Li}^{\mathrm{a}}{ }^{\text {, Huiting Mao }}{ }^{\mathrm{c}}$, Robert Talbot ${ }^{\mathrm{d}}$, Xiaoling Nie ${ }^{\mathrm{a}}$, \\ Chen Wu ${ }^{\text {a }}$, Yanfang Zhao ${ }^{\mathrm{e}}$, Chenxiao Hou ${ }^{\mathrm{e}}$, Guirong Wang ${ }^{\mathrm{f}}$, Jie Zhou ${ }^{\mathrm{b}}$, Guanghao Qie ${ }^{\text {a }}$
}

\begin{abstract}
Measurements of atmospheric particulate mercury $(\mathrm{PHg}$ ) were conducted at a suburban site in Jinan, China from June 2014 to December 2015. The average PHg concentration was $508.5 \pm$ $402.7 \mathrm{pg} \mathrm{m}^{-3}$, and the average $\mathrm{Hg}$ content in $\mathrm{PM}_{2.5}$ (particles with a diameter of $2.5 \mu \mathrm{m}$ or less) was $6.60 \pm 5.82 \mu \mathrm{g} \mathrm{g}^{-1}$. Both $\mathrm{PHg}$ and $\mathrm{Hg}$ content in $\mathrm{PM}_{2.5}$ aerosols were comparable to levels in some cities in China and were much higher than in cities in North America and Europe. Weak correlations were found between PHg and meteorological parameters. The correlations between $\mathrm{PHg}$ and other pollutants in ambient air, including $\mathrm{SO}_{2}, \mathrm{CO}$ and $\mathrm{NO}_{x}$, together with their wind dependence were used for source analysis, which suggested coal-fired industries, cement plants and traffic emissions as potential local sources for the site. Cluster analysis of 36-h backward trajectories suggested that the regional transport from southwestern Shandong Province also contributed to PHg in Jinan.
\end{abstract}

Keywords: Atmospheric particulate mercury; Source analysis; Meteorological parameter; Cluster analysis; Jinan

\footnotetext{
* Corresponding authors. Address: School of Environmental Science and Engineering, Shandong University, Jinan, 250100, China. Tel./fax: +86 53188361157 (Y. Wang). Address: Shandong Provincial Environmental Information and Monitoring Centre, Jinan, 250101, China (Y. Li).

E-mail addresses: wy@sdu.edu.cn (Y. Wang), atmosphere2016@163.com (Y. Li).
} 


\section{Introduction}

Mercury $(\mathrm{Hg})$ is a highly toxic heavy metal that attracts global concern due to its persistence and bioaccumulation in food chains. It can endanger both human health and the environment. The atmosphere plays a dominant role in mercury transformation in various environments and allows mercury to enter remote areas through long-range transportation (Pirrone and Mahaffey, 2005; Wängberg et al., 2001). Mercury can be released into the atmosphere from both natural sources (e.g., volcanoes, forest fire, geothermal vents and evaporation from soil and water surfaces) and anthropogenic sources (e.g., coal combustion, non-ferrous metal production, cement production and waste incineration) (Pacyna et al., 2010; Pirrone et al., 2010; Zhang et al., 2015a).

Atmospheric mercury generally exists in three forms: gaseous elemental mercury (GEM), reactive gaseous mercury (RGM) and particulate mercury ( $\mathrm{PHg}$ ). Each mercury species has different physical and chemical properties and, therefore, different behaviors. GEM is the predominant form of atmospheric mercury, has a residence time of several months to a year and can be transported over long distances (Schroeder and Munthe, 1998). RGM has a much shorter residence time (hours to several days) compared with GEM due to its high solubility and reactivity (Laurier et al., 2003). PHg has high solubility, deposition velocity and scavenging coefficients. $\mathrm{PHg}$ residence time generally ranges from hours to several weeks depending on the particle size (Schroeder and Munthe, 1998). Although PHg accounts for a small part of total atmospheric mercury (less than 10\%), it plays a vital role in the deposition of atmospheric mercury and therefore the global mercury biogeochemical cycle.

However, long-term monitoring studies of $\mathrm{PHg}$ are limited, and their relationships with physical and chemical parameters indicated PHg levels were mostly related to local emission, air mass transport, meteorological parameters and chemical transformation. For example, Mao et al. (2012) suggested that PHg was influenced by wind speed, solar radiation and temperature, whereas relative humidity and precipitation had negligible impact on PHg based on their 1.5 year PHg monitoring study in New England, USA. Poissant et al. (2005) conducted a one-year PHg measurement campaign in southern Quebec, Canada and found that PHg was correlated significantly with solar radiation and wind speed. They also found that $\mathrm{PHg}$ was associated with air mass transport and transformation from $\mathrm{Hg}^{0}$. Two-year PHg dataset collected from Lyman and Gustin (2009) exhibited that PHg was impacted primarily by local sources and by meteorological conditions in Reno, USA. These studied measured $\mathrm{PHg}$ on $\mathrm{PM}_{2.5}$ (particles with a diameter of 2.5 $\mu \mathrm{m}$ or less) using Tekran 1135, instead of manual sampling and analysis.

In recent decades, mercury contamination has become a serious problem in China. Previous studies have shown that approximately two-thirds of global anthropogenic mercury emissions are from Asia and that China is the largest worldwide contributor (Pacyna et al., 2010; Pirrone et al., 2010). Higher emissions may lead to higher atmospheric mercury levels. Several atmospheric mercury measurements have been conducted in Chinese cities and remote areas (Fang et al., 2004; Feng et al., 2004; Fu et al., 2011; Fu et al., 2008; Fu et al., 2012; Wang et al., 2016; Wang et al., 2006; Xiu et al., 2009; Xiu et al., 2005; Xu et al., 2015; Zhang et al., 2015b; Zhu et al., 2014). All of these studies reported much higher mercury species concentrations than studies in developed countries. However, only a few of them focused on PHg in comparison to GEM and RGM.

The updated anthropogenic mercury emission inventories show that Shandong Province ranks second of all of the provinces in China because of the contributions of industrial coal 
consumption and cement production (Zhang et al., 2015a). Jinan, the capital of Shandong Province, is a typical area that suffers severe air pollution especially particulate matter contamination. This area could be regarded as an important pathway of mercury transport in eastern China. Studies related to $\mathrm{PM}_{2.5}$ have been conducted in Jinan and improve our understanding of the chemical and physical characteristics, sources, and health impacts of $\mathrm{PM}_{2.5}$ (Gao et al., 2011; Wang et al., 2012; Yang et al., 2013; Yang et al., 2012). However, no atmospheric particulate mercury data in Jinan has been reported.

To our knowledge, this study is the first long-term monitoring study of $\mathrm{PHg}$ in this area. The purposes of this study are to: (1) report the levels of $\mathrm{PHg}$ concentration and the mercury content in $\mathrm{PM}_{2.5}$ in Jinan; (2) investigate the relationship between PHg and meteorological parameters, as well as other pollutants in the ambient air; (3) discuss the impact of long-range transport on PHg; and (4) attempt to identify the potential sources of PHg in Jinan.

\section{Methods}

\subsection{Site description}

The experiment was conducted in Jinan in eastern China (Fig. 1), a typical medium-sized city with increasing population and heavy pollution. The sampling site $\left(36.67^{\circ} \mathrm{N}, 117.03^{\circ} \mathrm{E}\right)$ was on the roof of a two-story building in Environmental Monitoring Central Station of Shandong Province, approximately $7 \mathrm{~m}$ above ground. It is a suburban site, surrounded by a main road with heavy traffic, residential communities and farmlands. There are a few large industries near the site.

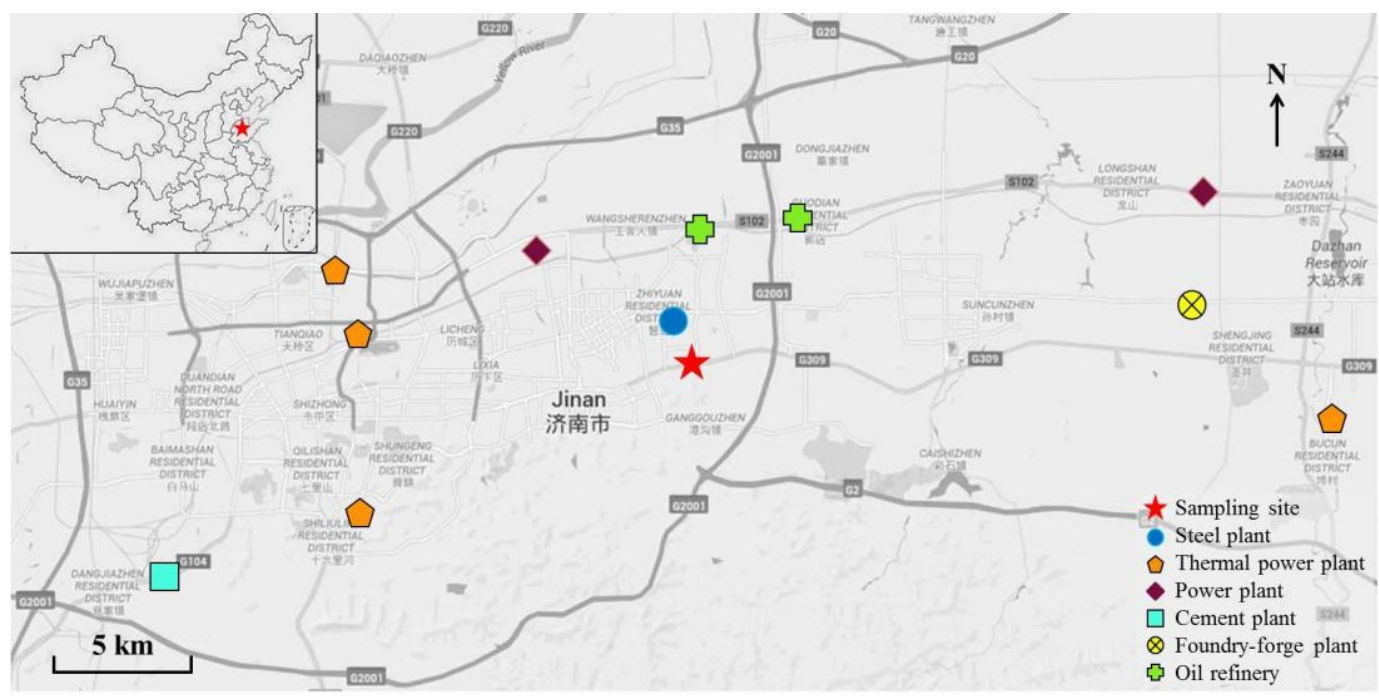

Fig. 1. Location of sampling site in Jinan and the distribution of main industries.

\section{2. $\mathbf{P M}_{2.5}$ collection}

In this study, $\mathrm{PM}_{2.5}$ samples were collected using a Thermo Scientific Partisol 200i sampler (Thermo Scientific, USA) with Teflon filters $(47 \mathrm{~mm}, 1 \mu \mathrm{m}$ pore size) at a flow rate of $16.7 \mathrm{~L}$ $\mathrm{min}^{-1}$. Each sample was collected for $23 \mathrm{~h}$, from 10:00 am to 9:00 am the next morning.

Before sampling, Teflon filters were baked at $100{ }^{\circ} \mathrm{C}$ for $3 \mathrm{~h}$ to remove any deposited 
compounds, conditioned in a desiccator for $24 \mathrm{~h}$, and then weighed with a $0.01 \mathrm{mg}$ precision microbalance. After sampling, the filters were equilibrated in a desiccator for $24 \mathrm{~h}$ prior to weighing and stored at $-18{ }^{\circ} \mathrm{C}$ until analysis. Petri dishes were used to store and transport the filters.

The sampling campaign started on 3 June 2014 and ended on 28 December 2015. A total of 357 samples were collected during the sampling period.

\subsection{Particulate mercury analysis}

To analyze PHg, a Teflon filter was put into a $20 \mathrm{~mL}$ brown high-borosilicate glass bottle and soaked by $5 \mathrm{~mL} \mathrm{BrCl}$ for $24 \mathrm{~h}$. All mercury-containing compounds were oxidized by a digestion solution to soluble $\mathrm{Hg}^{\mathrm{II}}$ species. Then $15 \mathrm{~mL}$ ultrapure water was added to the bottle, which diluted the sample to $0.5 \% \mathrm{BrCl}$. Prior to analysis, $0.1 \mathrm{~mL} \mathrm{NH}_{2} \mathrm{OH} \cdot \mathrm{HCl}$ was pipetted into the sample to reduce the halogens. Atomic Fluorescence Spectrometry (AFS) was applied to determine the concentration of mercury after the $\mathrm{Hg}^{\mathrm{II}}$ in the extract was reduced by $\mathrm{KBH}_{4}$ to form $\mathrm{Hg}^{0}$. This analysis method was used previously by Talbot et al. (2011).

\subsection{Backward trajectories analysis}

To identify the source of long range transport and regional transport of $\mathrm{PHg}$ and to study the impact of air mass movements on PHg, the Hybrid Single Particle Lagrangian Integrated Trajectory (HYSPLIT) model developed by the National Ocean and Atmospheric Administration (NOAA) (Draxler and Rolph, 2003) was used with the Global Data Assimilation System (GDAS) meteorological dataset (spatial resolution $1^{\circ}$ ). We calculated 36-h backward air mass trajectories ending at the sampling site with a starting height of $1,000 \mathrm{~m}$ above ground level. Then, we performed cluster analysis of trajectories.

\subsection{Meteorological parameters and criteria pollutants data}

Hourly meteorological data for the sampling site, including wind direction, wind speed, air temperature, relative humidity and surface pressure and air pollutants data including $\mathrm{O}_{3}, \mathrm{SO}_{2}, \mathrm{CO}$, $\mathrm{NO}, \mathrm{NO}_{2}$ and $\mathrm{NO}_{\chi}$ were provided by Environmental Information and Monitoring Center of Shandong Province.

\subsection{Quality assurance}

Field blank filters were measured to reduce the artifacts. The field blank filters were treated similarly to other samples. Field blanks include the filter blanks, reagent blanks, transportation blanks and storage blanks; therefore, field blanks were subtracted from the measured values.

To prevent contamination, the collector head was cleaned with ethyl alcohol before use. The tweezers, scissors, beakers, pipettes and sample bottles were soaked in $20 \% \mathrm{HNO}_{3}$ solution, $5 \%$ $\mathrm{BrCl}$, and $5 \% \mathrm{HCl}$ solution in sequence, for more than $24 \mathrm{~h}$ respectively, and then were rinsed five times with ultrapure water. 


\section{Results and discussion}

\subsection{Concentrations of PHg in ambient air}

The average concentration of $\mathrm{PHg}$ in $\mathrm{PM}_{2.5}$ during the study period was $508.5 \pm 402.7 \mathrm{pg} \mathrm{m}^{-3}$, with the median concentration of $441.3 \mathrm{pg} \mathrm{m}^{-3}$. Table 1 summarized some studies of $\mathrm{PHg}$ worldwide. The PHg concentration in Jinan was over ten times higher than that in remote areas of China and was of the same order of magnitude as in other cities in China. It was lower than that of Beijing and Nanjing. However it should be noted that the particulate matter collected in our study was $\mathrm{PM}_{2.5}$; whereas $\mathrm{PHg}$ measured in Beijing and Nanjing were referred to TSP and $\mathrm{PM}_{10}$, respectively. PHg in Jinan was slightly higher than that of cities such as Guiyang and Shanghai but was nearly three-fold higher than coastal cities such as Xiamen, which are relatively cleaner than inland cities. Compared globally, the level of PHg in Jinan significantly exceeded that of most cities in East Asia, Europe and North America by nearly two orders of magnitude. This may result from the differences in energy structures, industrial structures and pollution control technologies between China and developed countries. Only the values observed from areas that were heavily impacted by strong anthropogenic sources (e.g., Zabrze and Mexico City) such as cement production, petroleum refining, non-ferrous metal refining and waste incineration could be comparable. It is speculated that Jinan, as well as other cities in China, probably has more $\mathrm{Hg}$ emission sources than developed countries.

\section{Table 1}

Comparison of $\mathrm{PHg}$ concentration at various locations worldwide

\begin{tabular}{llllll}
\hline Location & Classification & Time & Cutoff size & PHg $\left(\mathrm{pg} \mathrm{m}^{-3}\right)$ & Reference \\
\hline Jinan, China & Suburban & Jun 2014-Dec 2015 & $\mathrm{PM}_{2.5}$ & $508.5 \pm 402.7$ & This study \\
Beijing, China & Urban & Jan, Feb, Sep 1998 & $\mathrm{TSP}$ & $1180 \pm 820$ & Wang et al. (2006) \\
Nanjing, China & Urban & Jun 2011-Feb 2012 & $\mathrm{PM}_{10}$ & $1100 \pm 570$ & Zhu et al. (2014) \\
Guiyang, China & Urban & Aug-Dec 2009 & $\mathrm{PM}_{2.5}$ & $368 \pm 676$ & Fu et al. (2011) \\
Shanghai, China & Urban & Nov 2013-Oct 2014 & $\mathrm{PM}_{2.5}$ & $300 \pm 310$ & Duan et al. (2016) \\
Xiamen, China & Coastal & Mar 2012-Feb 2013 & $\mathrm{PM}_{2.5}$ & $174.4 \pm 280.6$ & Xu et al. (2015) \\
Mt. Gongga, China & Remote & May 2005-Apr 2006 & $\mathrm{TSP}$ & 30.7 & Fu et al. (2008) \\
Mt. Waliguan, China & Remote & Sep 2007-Sep 2008 & $\mathrm{PM}_{2.5}$ & $19.4 \pm 18.1$ & Fu et al. (2012) \\
Seoul, Korea & Urban & Feb 2005-Feb 2006 & $\mathrm{PM}_{2.5}$ & $23.9 \pm 19.6$ & Kim et al. (2009) \\
Cape Hedo, Japan & Remote & Mar-May, 2004 & $\mathrm{PM}_{2.5}$ & $3.0 \pm 2.5$ & Chand et al. (2008) \\
Nova Scotia, Canada & Urban & Jan 2010-Dec 2011 & $\mathrm{PM}_{2.5}$ & $2.3 \pm 3.1$ & Cheng et al. (2013) \\
Thompson Farm, USA & Coastal & Feb 2009-Aug 2010 & $\mathrm{PM}_{2.5}$ & $0.19-1.14$ & Mao and Talbot (2012) \\
Rochester, USA & Suburban & Dec 2007-Nov 2009 & $\mathrm{PM}_{2.5}$ & $8.7 \pm 12.8$ & Choi et al. (2013) \\
Chicago, USA & Urban & Jul-Nov 2007 & $\mathrm{PM}_{2.5}$ & $9 \pm 20$ & Gratz et al. (2013) \\
Zabrze, Poland & Urban & Oct 2006-Apr 2007 & $\mathrm{PM}_{2.5}$ & 100.4 & Pyta et al. (2008) \\
Mexico City, USA & Urban & Mar 2006 & $\mathrm{PM}_{2.5}$ & $187 \pm 300$ & Rutter et al. (2009) \\
\hline
\end{tabular}

\footnotetext{
${ }^{\mathrm{a}}$ The range of median concentrations in different seasons.
} 


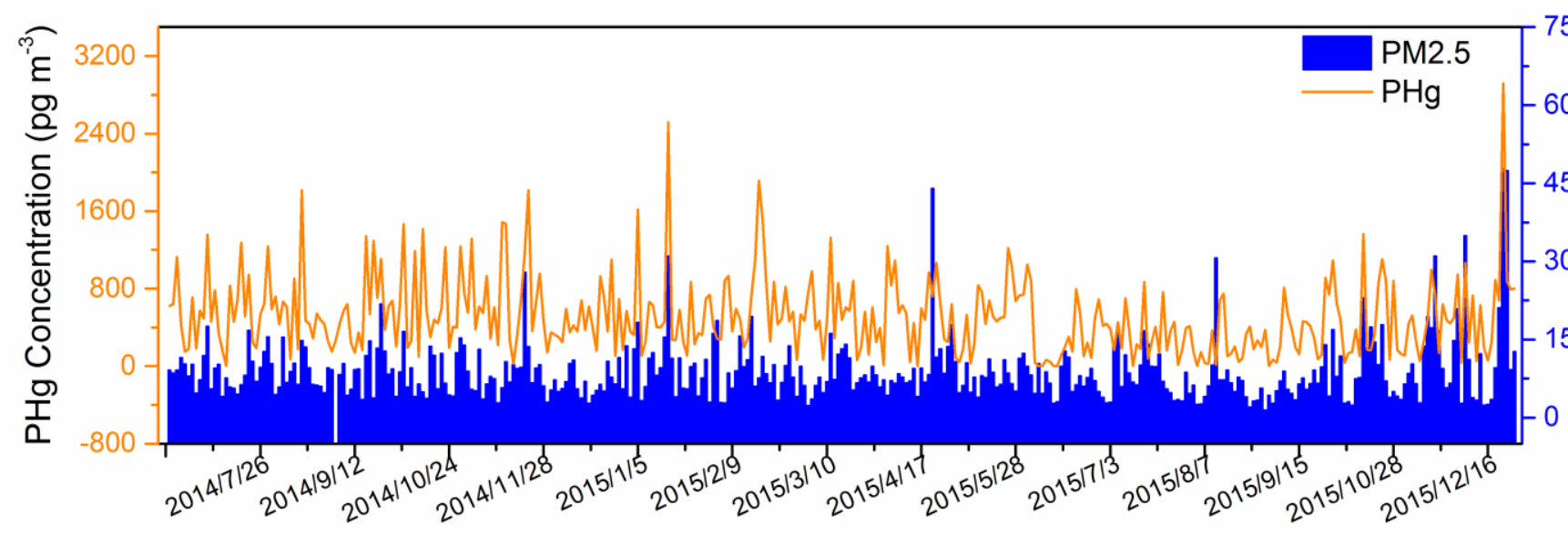

Fig.2. Time series of $\mathrm{PHg}$ and $\mathrm{PM}_{2.5}$ concentrations in Jinan during the study period.

Fig. 2 shows the time series of $\mathrm{PHg}$ and $\mathrm{PM}_{2.5}$ concentrations during the study period. $\mathrm{PHg}$ showed significant variability with some extremely high concentration episodes; this may indicate that the study site was impacted by strong nearby sources. The PHg concentrations showed higher levels during cold months compared with warm months. Similar monthly variations were observed by previous studies in China (Fang et al., 2004; Fu et al., 2008; Fu et al., 2012; Xiu et al., 2009; $\mathrm{Xu}$ et al., 2015) and are consistent with some observations outside of China (Cheng et al., 2013; Choi et al., 2013). This can be explained by more favorable condition for the formation of particle-phase mercury and more coal consumption in heating period during winter, along with divergent meteorological conditions between cold and warm seasons (Feng et al., 2004; Kim et al., 2012; Lyman and Gustin, 2009; Rutter and Schauer, 2007). The concentrations of PHg and $\mathrm{PM}_{2.5}$ showed significant positive correlation $(\mathrm{r}=0.358, \mathrm{p}<0.01)$, which revealed that the $\mathrm{PHg}$ concentration in the atmosphere was greatly influenced by the concentration of particles. It also suggested some common emission sources for $\mathrm{PHg}$ and $\mathrm{PM}_{2.5}$.

\subsection{Hg content in $\mathbf{P M}_{2.5}$}

To eliminate the effect of $\mathrm{PM}_{2.5}$ concentration, the mercury mass content in $\mathrm{PM}_{2.5}\left(\mathrm{PHg} / \mathrm{PM}_{2.5}\right)$ was calculated by dividing the mass of $\mathrm{Hg}$ on the filter $(\mu \mathrm{g})$ by the mass of particulate matter on the filter (g). During the study period, the average $\mathrm{PHg} / \mathrm{PM}_{2.5}$ was $6.60 \pm 5.82 \mu \mathrm{g} \mathrm{g}^{-1}$ and the median was $5.26 \mu \mathrm{g} \mathrm{g}^{-1}$. Compared with the mercury content in other sources, such as $0.019 \mu \mathrm{g} \mathrm{g}^{-1}$ in the soil of Shandong Province (CEM, 1990) and $0.18 \mu \mathrm{g} \mathrm{g}^{-1}$ in the coal from Shandong Province (Streets et al., 2005), $\mathrm{PM}_{2.5}$ in Jinan appeared to have a strong enrichment of mercury. $\mathrm{PHg} / \mathrm{PM}_{2.5}$ in Jinan was significantly higher than values reported from other cities domestically and abroad. Previous studies found that $\mathrm{Hg}$ content in fine particles was $0.2 \mu \mathrm{g} \mathrm{g}^{-1}$ in Okinawa

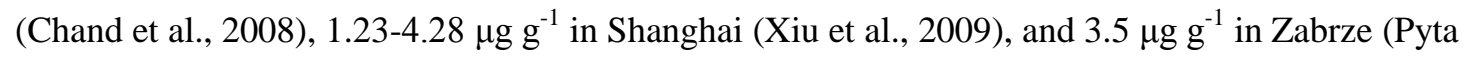
et al., 2008). The elevated $\mathrm{Hg}$ content in Jinan may reflect the strong anthropogenic mercury emission sources here. 


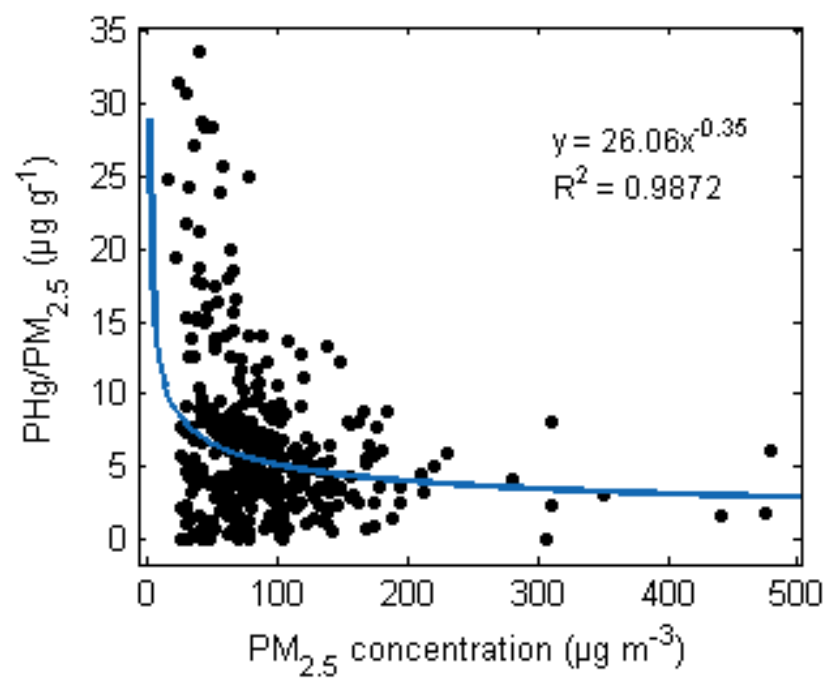

Fig.3. Relationship between $\mathrm{Hg}$ mass content in $\mathrm{PM}_{2.5}$ and $\mathrm{PM}_{2.5}$ concentration.

A power function existed between $\mathrm{PHg} / \mathrm{PM}_{2.5}$ and $\mathrm{PM}_{2.5}$ concentration $(\mathrm{p}<0.05)$ (Fig. 3). The highest values of $\mathrm{PHg} / \mathrm{PM}_{2.5}$ were seen when $\mathrm{PM}_{2.5}$ concentrations were at low levels $(<70 \mu \mathrm{g}$ $\mathrm{m}^{-3}$ ). Then $\mathrm{PHg} / \mathrm{PM}_{2.5}$ decreased rapidly as $\mathrm{PM}_{2.5}$ concentrations increased. When $\mathrm{PM}_{2.5}$ concentrations reached extremely high levels $\left(>250 \mu \mathrm{g} \mathrm{m}{ }^{-3}\right), \mathrm{PHg} / \mathrm{PM}_{2.5}$ values appeared to be relatively constant at very low values. One possible explanation is that particle size could affect $\mathrm{PHg} / \mathrm{PM}_{2.5}$ value. Study of $\mathrm{PM}_{2.5}$ size distribution has been conducted in Jinan. Xu (2011) reported that in Jinan when $\mathrm{PM}_{2.5}$ concentrations were elevated (i.e., haze days), particles tended to consist of coarser sizes; when $\mathrm{PM}_{2.5}$ concentrations were low (i.e., clear days), it was favorable for the existence of ultrafine particles. Previous studies demonstrated that mercury largely accumulated on ultrafine particles. Xiu et al. (2009) found that $47-60 \%$ of mercury in $\mathrm{PM}_{8}$ concentrated on $\mathrm{PM}_{1.6}$ in Shanghai, China. Kim et al. (2012) showed that 55-91\% of mercury in $\mathrm{PM}_{18}$ accumulated on $\mathrm{PM}_{1.8}$ in Seoul, Korea. In Jinan, on hazy days $\mathrm{PM}_{2.5}$ concentrations were elevated but $\mathrm{Hg}$ content in $\mathrm{PM}_{2.5}$ were low, whereas on clear days $\mathrm{PM}_{2.5}$ was comprised of more ultrafine particles with high $\mathrm{Hg}$ content. The ultrafine particles have larger surface area and could adsorb mercury more easily.

Considering the elevated values of PHg concentration and $\mathrm{Hg}$ content in Jinan, more attention should be paid to the influencing factors and sources of PHg.

\subsection{Influences of meteorological parameters}

As previous studies suggested, the temporal variation of $\mathrm{PHg}$ could be dependent on meteorological conditions. Table 2 shows the correlations between PHg concentration and meteorological parameters.

There was a significant negative correlation between $\mathrm{PHg}$ and temperature, especially during winter $(r=0.300, p<0.01)$. The fundamental reason was the impact of gas-particle partitioning, which plays an essential role in the formation of PHg in fine particles (Xiu et al., 2005). Gas-particle partitioning is highly dependent on temperature. Adsorption of gaseous $\mathrm{Hg}$ onto a fine particle is more efficient at low temperature; there is a widely recognized equation in Rutter and Schauer (2007) illustrating the anticorrelation between the partitioning coefficient and 
temperature. Also the increased emissions during wintertime heating periods should not be neglected, as coal combustion is commonly used for space heating, which emits both $\mathrm{Hg}$ and $\mathrm{PM}_{2.5}$. Higher particle concentrations also provided more room for increased GEM oxidation reactions to produce $\mathrm{PHg}$.

Table 2

Summary of Spearman's coefficients between PHg and meteorological parameters.

\begin{tabular}{|c|c|c|c|c|c|c|}
\hline & $\mathrm{PM}_{2.5}$ & Content & $\begin{array}{l}\text { Wind } \\
\text { Speed }\end{array}$ & Pressure & Humidity & Temperature \\
\hline $\mathrm{PHg}$ & $0.358^{* * *}$ & $0.781^{* * *}$ & $-0.114^{*}$ & $0.164^{* *}$ & $0.122^{*}$ & $-0.148^{* * *}$ \\
\hline $\mathrm{PM}_{2.5}$ & & $-0.217^{* *}$ & $-0.314^{* *}$ & -0.003 & $0.299^{* *}$ & 0.015 \\
\hline Content & & & 0.062 & $0.154^{* *}$ & -0.067 & $-0.139^{* *}$ \\
\hline Wind Speed & & & & -0.003 & $-0.251^{* *}$ & 0.001 \\
\hline Pressure & & & & & $-0.266^{* *}$ & $-0.883^{* *}$ \\
\hline Humidity & & & & & & $0.234^{* *}$ \\
\hline
\end{tabular}

$* *$ : the p-value $<0.01$

$*$ : the p-value $<0.05$

Surface pressure was positively correlated with PHg concentrations, which was in line with the negative correlation between temperature and PHg. It has reached an agreement that low (high) pressure was normally coupled with high (low) temperature and elevated (lowered) planet boundary layer height. Low pressure, along with high temperature and increased planet boundary layer height, could accelerate air mass exchange and mixing (Xu et al., 2015) and dilute PHg concentration in ambient air assuming constant emissions as a result.

PHg showed positive correlation with RH. Liquid water or droplets tend to form at higher RH. Several studies illustrated that mercury transformation could be accelerated by aqueous reactions or heterogenic reaction in the liquid phase. For example, Lin and Pehkonen (1999) reported that the weak acidic environment in droplets was favorable to reactions between gaseous mercury and ions such as $\mathrm{SO}_{3}{ }^{2-}, \mathrm{SO}_{4}{ }^{2-}, \mathrm{Cl}^{-}, \mathrm{HS}^{-}, \mathrm{S}^{2-}$ and $\mathrm{H}_{2} \mathrm{O}_{2}$. Subir et al. (2011) also summarized from the literature that gaseous elemental mercury was unlikely to react with $\mathrm{O}_{3}$ or $\mathrm{OH}$ in the gas phase due to the low reaction constant; however, gaseous elemental mercury could be converted to gaseous oxidized mercury by fast oxidation in the aqueous phase. Gaseous oxidized mercury behaves similarly to semi-volatile organic compounds and has been shown to partition onto aerosols at high RH (Pankow, 1993). These studies pointed to the pathway that PHg was formed via gaseous mercury adsorption onto particles followed by oxidation in aqueous phase at high RH.

The inverse correlation between PHg concentration and wind speed revealed that high $\mathrm{PHg}$ events were likely to occur at relatively low wind speed, alluding to the predominant effect of local emissions. The relationships between PHg concentration and wind speed and wind direction will be discussed further in Section 3.5.

The correlations between $\mathrm{PHg}$ and the meteorological parameters listed above were all significant. However, the relationships were weaker than in other studies in Holland (Gratz et al., 2013), Shanghai (Xiu et al., 2009) and Rochester (Choi et al., 2013). This may, in part, reflect that anthropogenic source emissions contributed more to $\mathrm{PHg}$ in the ambient air compared to the meteorological impacts. 


\subsection{Correlations with other pollutants in the ambient air}

Table 3 shows the correlations between $\mathrm{PHg}$ and other gaseous pollutants, including $\mathrm{SO}_{2}, \mathrm{CO}$, $\mathrm{O}_{3}, \mathrm{NO}, \mathrm{NO}_{2}$ and $\mathrm{NO}_{\chi}$. The strongest positive correlation was between $\mathrm{PHg}$ and $\mathrm{SO}_{2}$, the marker pollutant from coal burning, especially during winter $(\mathrm{r}=0.451, \mathrm{p}<0.01)$, consistent with the fact that coal burning is the largest anthropogenic mercury emission source to the atmosphere (Pacyna et al., 2010; Streets et al., 2005; Zhang et al., 2015a). China is the largest contributor to global anthropogenic $\mathrm{Hg}$ emissions by a large margin (Pacyna et al., 2010), and unlike cities in Europe and North America, coal burning is the main energy source in Jinan . Except for municipal space heating in cold seasons and industrial needs such as coal-fired power plants and coal-fired steel plants that operate all year round, equal attention should be paid to coal burning for producing heat and cooking food in small residential units of rural areas.

\section{Table 3}

Summary of Spearman's coefficients between PHg and other pollutants in the ambient air.

\begin{tabular}{|c|c|c|c|c|c|c|c|c|}
\hline & $\mathrm{PM}_{2.5}$ & Content & $\mathrm{SO}_{2}$ & $\mathrm{CO}$ & $\mathrm{O}_{3}$ & NO & $\mathrm{NO}_{2}$ & $\mathrm{NO}_{\chi}$ \\
\hline $\mathrm{PHg}$ & $0.358^{* * *}$ & $0.781^{* *}$ & $0.360^{* *}$ & $0.304^{* *}$ & -0.094 & $0.178^{* *}$ & $0.261^{* *}$ & $0.241^{* *}$ \\
\hline $\mathrm{PM}_{2.5}$ & & $-0.217^{* *}$ & $0.349^{* *}$ & $0.696^{* *}$ & -0.073 & $0.106^{*}$ & $0.398^{* *}$ & $0.305^{* *}$ \\
\hline Content & & & $0.150^{* *}$ & $0.104^{*}$ & -0.070 & 0.102 & 0.009 & 0.043 \\
\hline $\mathrm{SO}_{2}$ & & & & $0.339^{* *}$ & $-0.278^{* *}$ & $0.390^{* *}$ & $0.585^{* *}$ & $0.546^{* *}$ \\
\hline $\mathrm{CO}$ & & & & & $-0.237^{* *}$ & $0.307^{* *}$ & $0.433^{* *}$ & $0.414^{* *}$ \\
\hline $\mathrm{O}_{3}$ & & & & & & $-0.506^{* *}$ & $-0.517^{* *}$ & $-0.566^{* *}$ \\
\hline NO & & & & & & & $0.658^{* *}$ & $0.850^{* *}$ \\
\hline $\mathrm{NO}_{2}$ & & & & & & & & $0.944^{* *}$ \\
\hline
\end{tabular}

$* *$ : the p-value $<0.01$

$*$ : the p-value $<0.05$

The traffic emission tracers, $\mathrm{CO}$ and $\mathrm{NO}_{x}$, were both positively correlated with $\mathrm{PHg}$, which indicates traffic is another emission source in Jinan. Gasoline powered vehicles were found to emit various mercury species to the atmosphere, although not as much as from coal combustion (Won et al., 2007), which indicates that traffic emissions should be considered as an Hg source in the areas near heavy-duty roads. $\mathrm{CO}$ showed a strong positive correlation with $\mathrm{PM}_{2.5}$ in addition to the positive correlation with $\mathrm{PHg}$ which could be ascribed to combustion. Apart from coal combustion, other combustion such as mobile oil combustion is considered to emit $\mathrm{Hg}$ to the atmosphere (Zhang et al., 2015a). Moreover, $\mathrm{PM}_{2.5}$ was found to be contributed in part to traffic emissions in a previous study conducted in Jinan (Yang et al., 2013). This result supports our original assumption.

We did not find any correlation between $\mathrm{PHg}$ and $\mathrm{O}_{3}$ at our site. Positive correlations with $\mathrm{O}_{3}$, temperature and solar radiation, as well as negative correlation with relative humidity, could be an indication of the presence of photochemical processing (Xu et al., 2015) by which $\mathrm{Hg}^{0}$ could be efficiently converted into $\mathrm{Hg}^{\mathrm{II}}$ and deposited onto the particles. We could not find any similar correlations to those mentioned above. Future work is needed to demonstrate photochemical processes of mercury in Jinan. 


\subsection{Wind rose and PHg rose}

The wind rose at the sampling site during the study period is shown in Fig. 4A. The prevailing wind direction at our site was E-SSW, which accounted for $72 \%$ of the entire study period. The wind speed was generally low; $63 \%$ was under $1.5 \mathrm{~m} \mathrm{~s}^{-1}$.
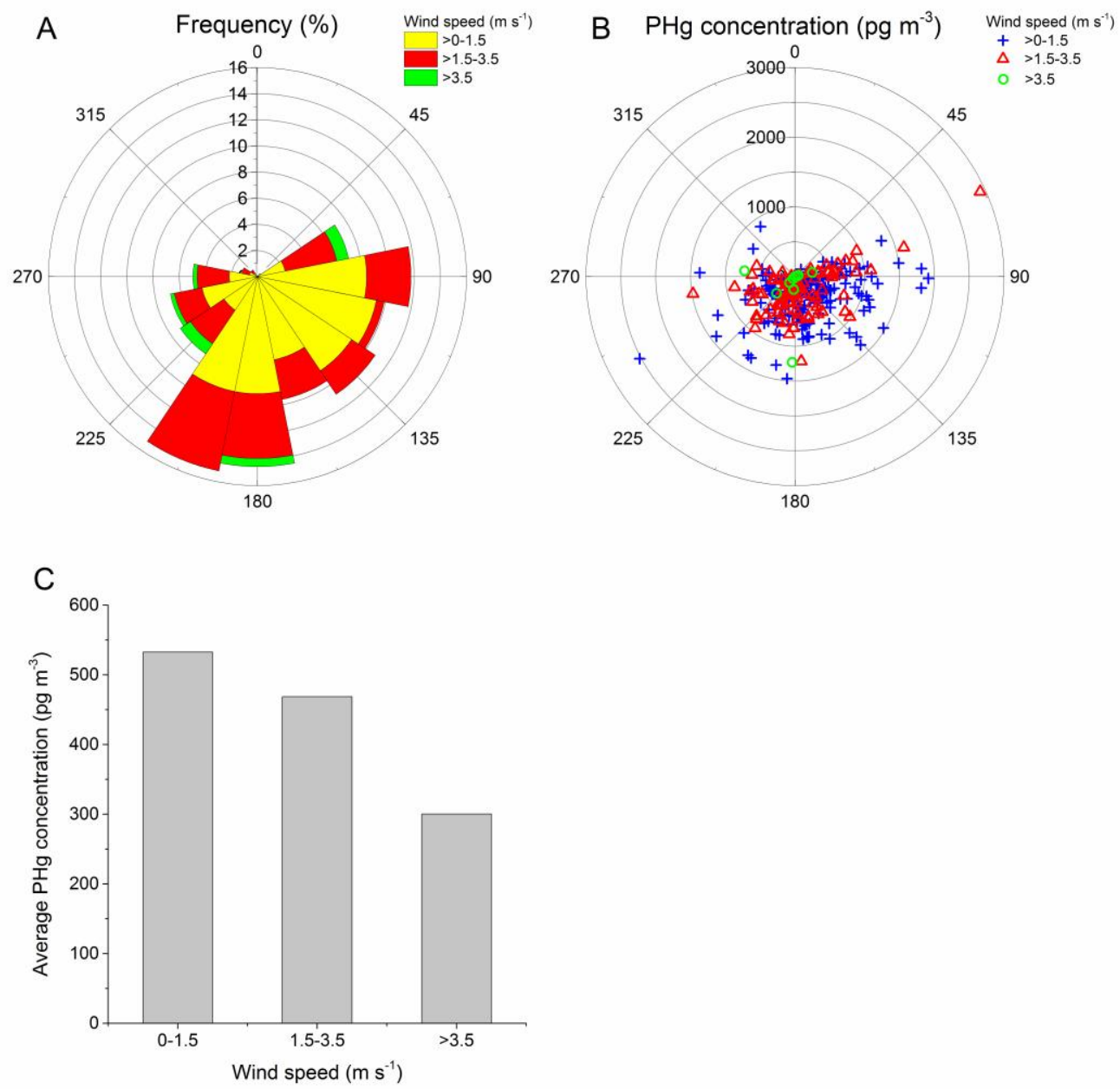

Fig.4. (A) Wind rose covering the whole study period; (B) PHg rose covering the whole study period; (C) $\mathrm{PHg}$ concentration versus wind speed

The PHg concentration under different wind speeds and wind directions is shown in Fig. 4B. The average PHg concentrations under wind speeds of $<1.5 \mathrm{~m} \mathrm{~s}^{-1}, 1.5-3.5 \mathrm{~m} \mathrm{~s}^{-1}$, and $>3.5 \mathrm{~m} \mathrm{~s}^{-1}$ were $532.72 \mathrm{pg} \mathrm{m}^{-3}, 468.61 \mathrm{pg} \mathrm{m}^{-3}$, and $300.12 \mathrm{pg} \mathrm{m}^{-3}$, respectively (Fig. 4C). It is notable that the $\mathrm{PHg}$ concentration under the condition of lower wind speed was evidently higher than that under higher wind speed and it fluctuated more strongly. Additionally, more than $80 \%$ of the high-PHg events (above the 90th percentile value) were observed at low wind speed $\left(<1.5 \mathrm{~m} \mathrm{~s}^{-1}\right)$. Apart from the strong mixing of air masses by wind at high speeds, this result indicates that nearby sources emissions may be the major contributors to $\mathrm{PHg}$ at our site. The industries adjacent to the site are of main concern. As listed in Fig. 1, an oil refinery and a steel plant are closely located to the north 
of the site. They are in an old industrial area and receive much attention because of their great consumption of coal, various emissions of air pollutants and relatively close distance to the urban area. Abdelhafez and Li (2015) showed that industrial activities contaminated the surrounding area with heavy metals. The city of Jinan is located in a basin, and hence air masses from all sources in the basin had been mixed at one point or the other in time, and thus those industrial sources in the northern parts of the city most likely impacted PHg measurements at the site. Traffic emission was another source. The road extremely close to the site is one of the broadest and most congested roads in Jinan, especially at rush hours in the morning and in the evening on weekdays. This increased the possibility for $\mathrm{PHg}$ emitted from gasoline powered vehicles to be observed at the site. Moreover, the local residential source should not be neglected. As our site is located in a suburban area, small residential units that produce heat and food with energy from coal combustion used low-grade coal mostly probably leading to significant $\mathrm{Hg}$ emissions.

PHg showed wind directional dependence in Jinan. Approximately $60 \%$ of the high $\mathrm{PHg}$ values were observed under NE-SE winds, and $37.5 \%$ were under S-W winds. High PHg values associated with high wind speed were observed under these directions. This result corresponded to the distribution of large point sources (Fig. 1). A power plant, a thermal power plant and a foundry-forge plant were the main point sources situated in the NE-E of the monitoring site, and two thermal power plants and a cement plant to the W-SW. These industrial plants were all coal-fired and have been identified as primary anthropogenic mercury sources (Pacyna et al., 2010; Zhang et al., 2015a). However, there were no apparent large point sources to the south and yet there were high concentrations of $\mathrm{PHg}$, which could be caused by regional transport.

In summary, coal-fired industrial plants, cement plants and traffic emissions were the dominant local sources of PHg in Jinan. Residential sources contributed a smaller but non-negligible portion. This is consistent with the results from Section 3.4.

\subsection{Backward trajectories analysis}

To further investigate the regional transport of PHg and its impact on PHg in Jinan, the 36-h air mass backward trajectories for a whole year (2015) were clustered and categorized into 4 sections, as shown in Fig. 5.

Cluster 1, cluster 2 and cluster 3 illustrated three major pathways for long-range transport. Cluster 1 originated from the Badain Jaran Desert in the west of Inner Mongolia and accounted for 7\%. Cluster 2 originated from Mongolia and southern Russia and accounted for $12 \%$. Cluster 3 originated from the Otindag Sand Land located in middle Inner Mongolia and accounted for $21 \%$. The origins of these clusters are widely recognized as the main sources of Asian dust. In air masses from these dust sources there were a large proportion of coarse particles that had weak adsorption of mercury. And the transport speed was high. Taken together, these conditions did not favor accumulation of mercury on particles. As a result, the concentration of PHg from cluster 1 was the lowest $\left(309.15 \mathrm{pg} \mathrm{m}^{-3}\right)$. However, cluster 2 and cluster 3 did not show a similar pattern with low PHg concentration. The PHg concentration from cluster 2 was $476.53 \mathrm{pg} \mathrm{m}^{-3}$ and from cluster 3 was $454.40 \mathrm{pg} \mathrm{m}^{-3}$. This result can be explained by the transport pathways. All three clusters originated from dust sources area of low mercury. When travelling on the pathway, air masses entrained particles from the heavy pollution areas increasing PHg concentrations. One of the most polluted areas, the Beijing-Tianjin-Hebei region, was on the path of cluster 2 and cluster 
3. The region was reported to have heavy $\mathrm{PHg}$ pollution because of a dense population and intensive industry (Streets et al., 2005; Wang et al., 2006), which allowed particles passing through to adsorb mercury. Therefore, high values of $\mathrm{PHg}$ were observed from these two clusters.

Cluster 4 accounted for $60 \%$ of the total trajectories and represented transport from the southwestern part of Shandong Province, which has been reported to be a major mercury contributor of the Province due to its dense distribution of coal-fired plants (Xiong et al., 2016). Cluster 4 originated in and passed through mercury polluted areas. Combined with the short transport distance and therefore long residence in polluted areas, mercury was accumulated on particles. This could explain the highest $\mathrm{PHg}$ concentration from cluster $4\left(491.96 \mathrm{pg} \mathrm{m}^{-3}\right)$. Therefore, cluster 4, the regional transport source, contributed to PHg in Jinan in addition to the local emission sources. Moreover, cluster 4 could be one possible explanation for the unidentified source of the high PHg concentrations in southerly wind noted in Section 3.5.

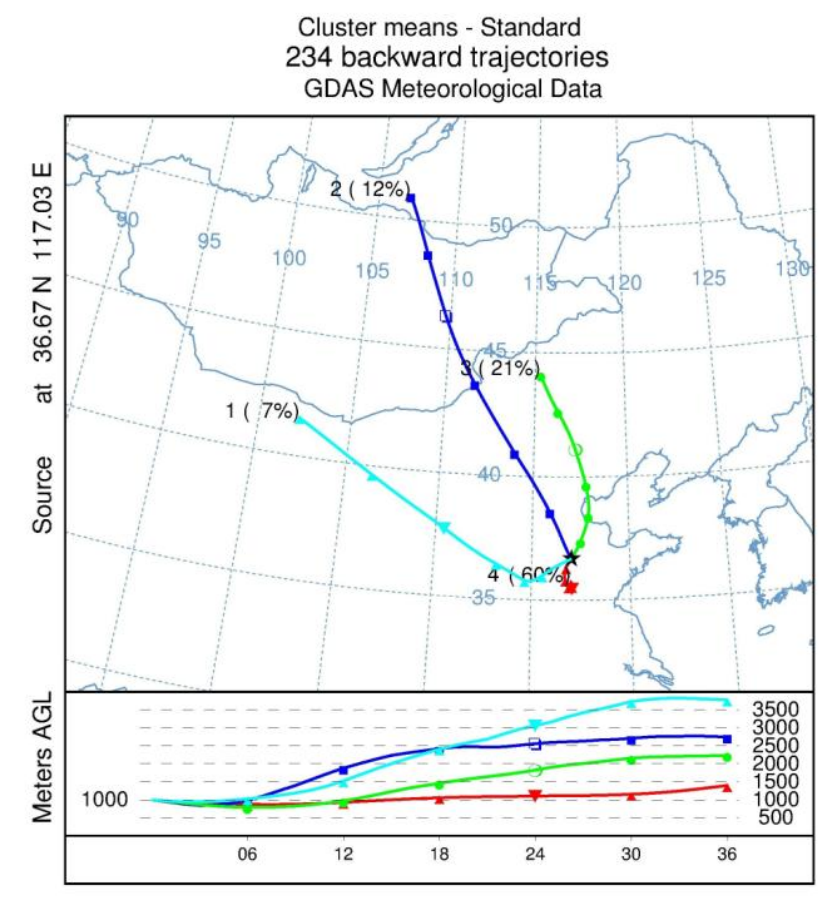

Fig. 5. Cluster analysis of HYSPLIT 36-h backward trajectories of air masses in Jinan. 


\section{Conclusions}

During June 2014 to December 2015, PHg and $\mathrm{Hg}$ content in $\mathrm{PM}_{2.5}$ were measured at a suburban site in Jinan. The average PHg concentration and $\mathrm{Hg}$ content were $508.5 \pm 402.7 \mathrm{pg} \mathrm{m}^{-3}$ and $6.60 \pm 5.82 \mu \mathrm{g} \mathrm{g}^{-1}$, respectively. Both $\mathrm{PHg}$ and $\mathrm{Hg}$ content were significantly higher than in cities in Europe and North America and were comparable to that in cities with heavy air pollution in China, which points to strong local emission sources.

$\mathrm{PHg}$ showed negative correlations with temperature and wind speed, and positive correlations with surface pressure and relative humidity. The correlations with meteorological parameters were all significant, albeit relatively weak.

For source identification, the positive correlations of $\mathrm{PHg}$ with $\mathrm{SO}_{2}, \mathrm{CO}$, and $\mathrm{NO}_{\chi}$ and the wind direction suggested that coal-fired industries, cement plants and traffic emissions from nearby congested roads were the major local sources. 36-h air mass back trajectories suggested that $\mathrm{PHg}$ in Jinan was less impacted by long-range transport originating from dust sources. In contrast, transport from southwestern part of Shandong Province could have contributed to the PHg levels observed in Jinan.

\section{Acknowledgements}

This work was supported by the National Science Foundation of China (41475115), the Science and Technology Development Project of Shandong Province (2014GSF117037) and the Major Technology Project of Independent Innovation of Shandong Province (2014GJJS0501). We also thank Elsevier for language editing. 


\section{Reference}

Abdelhafez AA, Li J. Environmental Monitoring of Heavy Metal Status and Human Health Risk Assessment in the Agricultural Soils of the Jinxi River Area, China. Human and Ecological Risk Assessment: An International Journal 2015; 21: 952-971.

Chand D, Jaffe D, Prestbo E, Swartzendruber PC, Hafner W, Weiss-Penzias P, et al. Reactive and particulate mercury in the Asian marine boundary layer. Atmospheric Environment 2008; 42: 7988-7996.

Cheng I, Zhang L, Blanchard P, Dalziel J, Tordon R. Concentration-weighted trajectory approach to identifying potential sources of speciated atmospheric mercury at an urban coastal site in Nova Scotia, Canada. Atmospheric Chemistry and Physics 2013; 13: 6031-6048.

Choi H-D, Huang J, Mondal S, Holsen TM. Variation in concentrations of three mercury (Hg) forms at a rural and a suburban site in New York State. Science of The Total Environment 2013; 448: 96-106.

Draxler R, Rolph G. HYSPLIT (HYbrid single-particle Lagrangian integrated trajectory) model access via NOAA ARL READY. NOAA Air Resources Laboratory, Silver Spring, MD. Dostupno na: http://ready. arl. noaa. gov/HYSPLIT. php (06. 06. 2010.) 2003.

Duan L, Xiu G, Feng L, Cheng N, Wang C. The mercury species and their association with carbonaceous compositions, bromine and iodine in PM2.5 in Shanghai. Chemosphere 2016; 146: $263-71$.

Fang F, Wang Q, Li J. Urban environmental mercury in Changchun, a metropolitan city in Northeastern China: source, cycle, and fate. Sci Total Environ 2004; 330: 159-70.

Feng X, Shang L, Wang S, Tang S, Zheng W. Temporal variation of total gaseous mercury in the air of Guiyang, China. Journal of Geophysical Research: Atmospheres 2004; 109.

Fu X, Feng X, Qiu G, Shang L, Zhang H. Speciated atmospheric mercury and its potential source in Guiyang, China. Atmospheric Environment 2011; 45: 4205-4212.

Fu X, Feng X, Zhu W, Zheng W, Wang S, Lu JY. Total particulate and reactive gaseous mercury in ambient air on the eastern slope of the Mt. Gongga area, China. Applied Geochemistry 2008; 23: 408-418

Fu XW, Feng X, Liang P, Deliger, Zhang H, Ji J, et al. Temporal trend and sources of speciated atmospheric mercury at Waliguan GAW station, Northwestern China. Atmospheric Chemistry and Physics 2012; 12: 1951-1964.

Gao X, Yang L, Cheng S, Gao R, Zhou Y, Xue L, et al. Semi-continuous measurement of water-soluble ions in PM2.5 in Jinan, China: Temporal variations and source apportionments. Atmospheric Environment 2011; 45: 6048-6056.

Gratz LE, Keeler GJ, Marsik FJ, Barres JA, Dvonch JT. Atmospheric transport of speciated mercury across southern Lake Michigan: Influence from emission sources in the Chicago/Gary urban area. Sci Total Environ 2013; 448: 84-95.

Kim P-R, Han Y-J, Holsen TM, Yi S-M. Atmospheric particulate mercury: Concentrations and size distributions. Atmospheric Environment 2012; 61: 94-102.

Kim S-H, Han Y-J, Holsen TM, Yi S-M. Characteristics of atmospheric speciated mercury concentrations (TGM, $\mathrm{Hg}(\mathrm{II})$ and $\mathrm{Hg}(\mathrm{p})$ ) in Seoul, Korea. Atmospheric Environment 2009; 43: 3267-3274.

Laurier FJ, Mason RP, Whalin L, Kato S. Reactive gaseous mercury formation in the North Pacific 
Ocean's marine boundary layer: A potential role of halogen chemistry. Journal of Geophysical Research: Atmospheres 2003; 108.

Lin C-J, Pehkonen SO. The chemistry of atmospheric mercury: a review. Atmospheric Environment 1999; 33: 2067-2079.

Lyman SN, Gustin MS. Determinants of atmospheric mercury concentrations in Reno, Nevada, U.S.A. Sci Total Environ 2009; 408: 431-8.

Mao H, Talbot R. Speciated mercury at marine, coastal, and inland sites in New England - Part 1: Temporal variability. Atmospheric Chemistry and Physics 2012; 12: 5099-5112.

Mao H, Talbot R, Hegarty J, Koermer J. Speciated mercury at marine, coastal, and inland sites in New England - Part 2: Relationships with atmospheric physical parameters. Atmospheric Chemistry and Physics 2012; 12: 4181-4206.

Pacyna EG, Pacyna JM, Sundseth K, Munthe J, Kindbom K, Wilson S, et al. Global emission of mercury to the atmosphere from anthropogenic sources in 2005 and projections to 2020. Atmospheric Environment 2010; 44: 2487-2499.

Pankow JF. A simple box model for the annual cycle of partitioning of semi-volatile organic compounds between the atmosphere and the earth's surface. Atmospheric Environment. Part A. General Topics 1993; 27: 1139-1152.

Pirrone N, Cinnirella S, Feng X, Finkelman RB, Friedli HR, Leaner J, et al. Global mercury emissions to the atmosphere from anthropogenic and natural sources. Atmospheric Chemistry and Physics 2010; 10: 5951-5964.

Pirrone N, Mahaffey KR. Where we stand on mercury pollution and its health effects on regional and global scales. Dynamics of Mercury Pollution on Regional and Global Scales:. Springer, 2005, pp. 1-21.

Poissant L, Pilote M, Beauvais C, Constant P, Zhang H. A year of continuous measurements of three atmospheric mercury species (GEM, RGM and $\mathrm{Hg}$ ) in southern Qubec, Canada. Atmospheric Environment 2005; 39: 1275-1287.

Pyta H, Rosik-Dulewska C, Czaplicka M. Speciation of Ambient Mercury in the Upper Silesia Region, Poland. Water, Air, and Soil Pollution 2008; 197: 233-240.

Rutter A, Snyder D, Stone E, Schauer J, Gonzalez-Abraham R, Molina L, et al. In situ measurements of speciated atmospheric mercury and the identification of source regions in the Mexico City Metropolitan Area. Atmospheric Chemistry and Physics 2009; 9: 207-220.

Rutter AP, Schauer JJ. The effect of temperature on the gas-particle partitioning of reactive mercury in atmospheric aerosols. Atmospheric Environment 2007; 41: 8647-8657.

Schroeder WH, Munthe J. Atmospheric mercury-an overview. Atmospheric Environment 1998; 32: 809-822.

Station CEM. Background values of elements in soils of China. Beijing, People's Republic of China: China Environmental Science and Technology Press, 1990.

Streets D, Hao J, Wu Y, Jiang J, Chan M, Tian H, et al. Anthropogenic mercury emissions in China. Atmospheric Environment 2005; 39: 7789-7806.

Subir M, Ariya PA, Dastoor AP. A review of uncertainties in atmospheric modeling of mercury chemistry I. Uncertainties in existing kinetic parameters - Fundamental limitations and the importance of heterogeneous chemistry. Atmospheric Environment 2011; 45: 5664-5676.

Talbot R, Mao H, Feddersen D, Smith M, Kim SY, Sive B, et al. Comparison of Particulate Mercury Measured with Manual and Automated Methods. Atmosphere 2011; 2: 1-20. 
Wängberg I, Munthe J, Pirrone N, Iverfeldt $\AA$, Bahlman E, Costa P, et al. Atmospheric mercury distribution in Northern Europe and in the Mediterranean region. Atmospheric Environment 2001; 35: 3019-3025.

Wang C, Ci Z, Wang Z, Zhang X, Guo J. Speciated atmospheric mercury in the marine boundary layer of the Bohai Sea and Yellow Sea. Atmospheric Environment 2016; 131: 360-370.

Wang X, Wang W, Yang L, Gao X, Nie W, Yu Y, et al. The secondary formation of inorganic aerosols in the droplet mode through heterogeneous aqueous reactions under haze conditions. Atmospheric Environment 2012; 63: 68-76.

Wang Z, Zhang X, Chen Z, Zhang Y. Mercury concentrations in size-fractionated airborne particles at urban and suburban sites in Beijing, China. Atmospheric Environment 2006; 40: 2194-2201.

Won JH, Park JY, Lee TG. Mercury emissions from automobiles using gasoline, diesel, and LPG. Atmospheric Environment 2007; 41: 7547-7552.

Xiong T, Jiang W, Gao W. Current status and prediction of major atmospheric emissions from coal-fired power plants in Shandong Province, China. Atmospheric Environment 2016; 124 : 46-52.

Xiu G, Cai J, Zhang W, Zhang D, Büeler A, Lee S, et al. Speciated mercury in size-fractionated particles in Shanghai ambient air. Atmospheric Environment 2009; 43: 3145-3154.

Xiu G, Jin Q, Zhang D, Shi S, Huang X, Zhang W, et al. Characterization of size-fractionated particulate mercury in Shanghai ambient air. Atmospheric Environment 2005; 39: 419-427.

Xu L, Chen J, Yang L, Niu Z, Tong L, Yin L, et al. Characteristics and sources of atmospheric mercury speciation in a coastal city, Xiamen, China. Chemosphere 2015; 119: 530-9.

$\mathrm{Xu}$ P. Characteristics of atmospheric particle number concentration and size distribution in urban Jinan. Ph.D. Thesis. Shandong University, China, 2011.

Yang L, Cheng S, Wang X, Nie W, Xu P, Gao X, et al. Source identification and health impact of PM2.5 in a heavily polluted urban atmosphere in China. Atmospheric Environment 2013; 75 : 265-269.

Yang L, Zhou X, Wang Z, Zhou Y, Cheng S, Xu P, et al. Airborne fine particulate pollution in Jinan, China: Concentrations, chemical compositions and influence on visibility impairment. Atmospheric Environment 2012; 55: 506-514.

Zhang L, Wang S, Wang L, Wu Y, Duan L, Wu Q, et al. Updated emission inventories for speciated atmospheric mercury from anthropogenic sources in China. Environ Sci Technol 2015a; 49: 3185-94.

Zhang Y, Liu R, Wang Y, Cui X, Qi J. Change characteristic of atmospheric particulate mercury during dust weather of spring in Qingdao, China. Atmospheric Environment 2015b; 102: 376-383.

Zhu J, Wang T, Talbot R, Mao H, Yang X, Fu C, et al. Characteristics of atmospheric mercury deposition and size-fractionated particulate mercury in urban Nanjing, China. Atmospheric Chemistry and Physics 2014; 14: 2233-2244. 
Table 1

Comparison of PHg concentration at various locations worldwide

\begin{tabular}{llllll}
\hline Location & Classification & Time & Cutoff size & PHg $\left(\mathrm{pg} \mathrm{m}^{-3}\right)$ & Reference \\
\hline Jinan, China & Suburban & Jun 2014-Dec 2015 & $\mathrm{PM}_{2.5}$ & $508.5 \pm 402.7$ & This study \\
Beijing, China & Urban & Jan, Feb, Sep 1998 & $\mathrm{TSP}$ & $1180 \pm 820$ & Wang et al. (2006) \\
Nanjing, China & Urban & Jun 2011-Feb 2012 & $\mathrm{PM}_{10}$ & $1100 \pm 570$ & Zhu et al. (2014) \\
Guiyang, China & Urban & Aug-Dec 2009 & $\mathrm{PM}_{2.5}$ & $368 \pm 676$ & Fu et al. (2011) \\
Shanghai, China & Urban & Nov 2013-Oct 2014 & $\mathrm{PM}_{2.5}$ & $300 \pm 310$ & Duan et al. (2016) \\
Xiamen, China & Coastal & Mar 2012-Feb 2013 & $\mathrm{PM}_{2.5}$ & $174.4 \pm 280.6$ & Xu et al. (2015) \\
Mt. Gongga, China & Remote & May 2005-Apr 2006 & $\mathrm{TSP}$ & 30.7 & Fu et al. (2008) \\
Mt. Waliguan, China & Remote & Sep 2007-Sep 2008 & $\mathrm{PM}_{2.5}$ & $19.4 \pm 18.1$ & Fu et al. (2012) \\
Seoul, Korea & Urban & Feb 2005-Feb 2006 & $\mathrm{PM}_{2.5}$ & $23.9 \pm 19.6$ & Kim et al. (2009) \\
Cape Hedo, Japan & Remote & Mar-May, 2004 & $\mathrm{PM}_{2.5}$ & $3.0 \pm 2.5$ & Chand et al. (2008) \\
Nova Scotia, Canada & Urban & Jan 2010-Dec 2011 & $\mathrm{PM}_{2.5}$ & $2.3 \pm 3.1$ & Cheng et al. (2013) \\
Thompson Farm, USA & Coastal & Feb 2009-Aug 2010 & $\mathrm{PM}_{2.5}$ & $0.19-1.14^{\mathrm{a}}$ & Mao and Talbot (2012) \\
Rochester, USA & Suburban & Dec 2007-Nov 2009 & $\mathrm{PM}_{2.5}$ & $8.7 \pm 12.8$ & Choi et al. (2013) \\
Chicago, USA & Urban & Jul-Nov 2007 & $\mathrm{PM}_{2.5}$ & $9 \pm 20$ & Gratz et al. (2013) \\
Zabrze, Poland & Urban & Oct 2006-Apr 2007 & $\mathrm{PM}_{2.5}$ & 100.4 & Pyta et al. (2008) \\
Mexico City, USA & Urban & Mar 2006 & $\mathrm{PM}_{2.5}$ & $187 \pm 300$ & Rutter et al. (2009) \\
\hline
\end{tabular}

${ }^{a}$ The range of median concentrations in different seasons.

Table 2

Summary of Spearman's coefficients between PHg and meteorological parameters.

\begin{tabular}{|c|c|c|c|c|c|c|}
\hline & $\mathrm{PM}_{2.5}$ & Content & $\begin{array}{l}\text { Wind } \\
\text { Speed }\end{array}$ & Pressure & Humidity & Temperature \\
\hline $\mathrm{PHg}$ & $0.358^{* * *}$ & $0.781^{* * *}$ & $-0.114^{*}$ & $0.164^{* *}$ & $0.122^{*}$ & $-0.148^{* *}$ \\
\hline $\mathrm{PM}_{2.5}$ & & $-0.217^{* *}$ & $-0.314^{* *}$ & -0.003 & $0.299^{* *}$ & 0.015 \\
\hline Content & & & 0.062 & $0.154^{* *}$ & -0.067 & $-0.139^{* *}$ \\
\hline Wind Speed & & & & -0.003 & $-0.251^{* *}$ & 0.001 \\
\hline Pressure & & & & & $-0.266^{* *}$ & $-0.883^{* *}$ \\
\hline Humidity & & & & & & $0.234^{* *}$ \\
\hline
\end{tabular}


Table 3

Summary of Spearman's coefficients between $\mathrm{PHg}$ and other pollutants in the ambient air.

\begin{tabular}{|c|c|c|c|c|c|c|c|c|}
\hline & $\mathrm{PM}_{2.5}$ & Content & $\mathrm{SO}_{2}$ & $\mathrm{CO}$ & $\mathrm{O}_{3}$ & $\mathrm{NO}$ & $\mathrm{NO}_{2}$ & $\mathrm{NO}_{\alpha}$ \\
\hline $\mathrm{PHg}$ & $0.358^{* *}$ & $0.781^{* * *}$ & $0.360^{* *}$ & $0.304^{* *}$ & $\begin{array}{l}-0.094 \\
\end{array}$ & $0.178^{* *}$ & $0.261^{* *}$ & $0.241^{* * *}$ \\
\hline $\mathrm{PM}_{2.5}$ & & $-0.217^{* *}$ & $0.349^{* *}$ & $0.696^{* *}$ & -0.073 & $0.106^{*}$ & $0.398^{* *}$ & $0.305^{* *}$ \\
\hline Content & & & $0.150^{* *}$ & $0.104^{*}$ & -0.070 & 0.102 & 0.009 & 0.043 \\
\hline $\mathrm{SO}_{2}$ & & & & $0.339^{* *}$ & $-0.278^{* *}$ & $0.390^{* * *}$ & $0.585^{* *}$ & $0.546^{* *}$ \\
\hline $\mathrm{CO}$ & & & & & $-0.237^{* *}$ & $0.307^{* * *}$ & $0.433^{* * *}$ & $0.414^{* *}$ \\
\hline $\mathrm{O}_{3}$ & & & & & & $-0.506^{* *}$ & $-0.517^{* *}$ & $-0.566^{* *}$ \\
\hline NO & & & & & & & $0.658^{* * *}$ & $0.850^{* *}$ \\
\hline $\mathrm{NO}_{2}$ & & & & & & & & $0.944^{* *}$ \\
\hline
\end{tabular}

$* *$ : the p-value $<0.01$

$*$ : the p-value $<0.05$ 


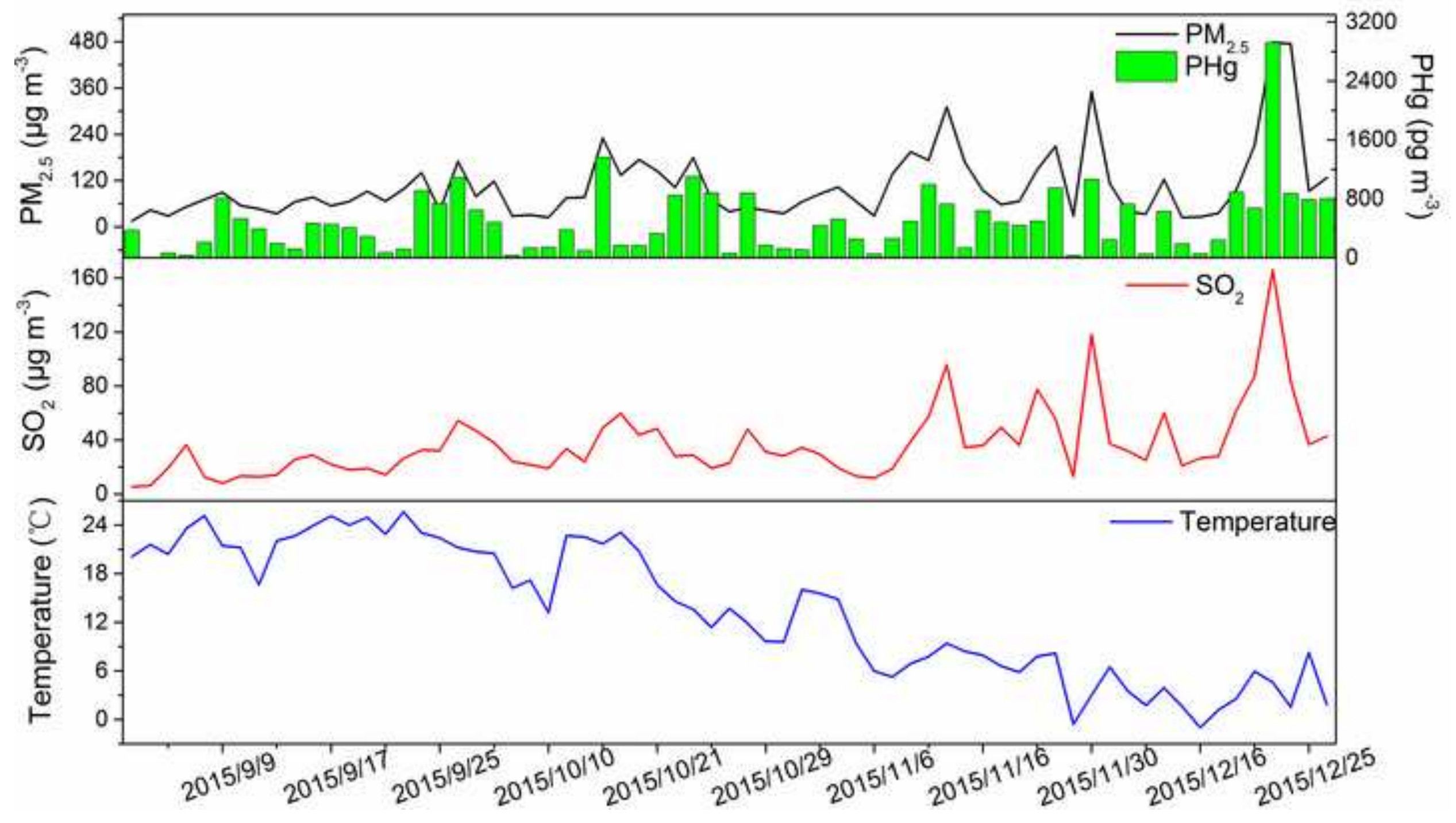

